\title{
On the issue of fluctuations in the extreme maximum runoff under the conditions of the expected climate change in the Marmarik river basin
}

\author{
Varduhi Margaryan ${ }^{1, *}$, and Elena Fedotova ${ }^{2,3}$ \\ ${ }^{1}$ Yerevan State University, Department of Physical Geography and Hydrometeorology, Faculty of \\ Geography and Geology, Yerevan, Armenia \\ ${ }^{2}$ Sukachev Institute of forest SB RAS, FRC KSC SB RAS, Krasnoyarsk, Russian Federation \\ ${ }^{3} \mathrm{SFU}$, Krasnoyarsk, Russian Federation
}

\begin{abstract}
The paper analyzes the peculiarities of formation of the absolute maximum runoff of the Marmarik river evaluates the patterns of multi-year fluctuations of maximum runoff rates in different river sites and gives a forecast of the maximum runoff in the context of global climate change. Absolute values of the maximum river runoff for different scenarios of climate change are estimated. The actual observational data of Armhydromet for maximum runoff rate, the air temperature and precipitation were used as the source material. As a result of the study, it turned out that there is only a tendency to decrease in the values of maximum runoff. It turned out that for all scenarios and cases in the Marmarik river basin, a different degree of changes in the maximum flow is observed. Moreover, the largest decrease in the maximum runoff of the Marmarik river basin is expected under the conditions of an increase in the average air temperature of the spring season by 2,7-3,9 degrees Celsius and a decrease in the amount of spring atmospheric precipitation by 2,4 $2,6 \%$.
\end{abstract}

\section{Introduction}

The analysis and estimation of the multi-year fluctuations of extreme maximum runoff rates in the context of global climate change becomes of an increasing importance. Notably, it is essential for engineering purposes and the exploitation of the hydraulic constructions, as well as for the organization of damage-preventing measures. Since the manifestations of the current climate change may be observed both on global and regional scales, their evaluation is one of the primary tasks that concern humanity. Moreover, the analysis of the maximum runoff rates is of great importance as a guarantee for stable development and promising economic growth. It is necessary to highlight that the Marmarik river is the main and most water-abundant inflow of the Hrazdan river. The regulation of the Marmarik river water level permits to decrease the water releases from lake Sevan, which is a strategic

\footnotetext{
* Corresponding author: vmargaryan@ysu.am
} 
fresh water storage site of the Republic. The river waters are exploited for irrigational purposes, as well as for supplying water to industrial enterprises. The river valley holds a large recreational potential, hosting a number of operating summer holiday houses. The Marmarik river valley contains a source of the mineral water "Hanqavan". It is the site of the yearly students' educational practice, such as hydrology.
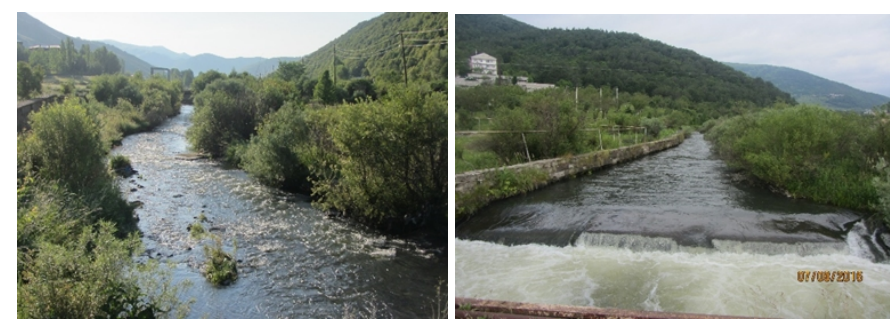

Fig. 1. Marmarik river

Therefore, the aim of this investigation is to analyze and evaluate the patterns of fluctuation of the maximum runoff rates in the Marmarik river basin within the scope of the expected climate change. To reach this aim, the following research tasks have been formulated and solved:

- $\quad$ to process and evaluate the hydro- and meteorological elements of the basin;

- $\quad$ to determine and analyze the specificities of space-time distribution of the extreme maximum runoff rates of the basin rivers;

- $\quad$ to forecast and evaluate the maximum runoff in the context of the forecasted future climate change.

\section{Study areas, Data and Methods}

In order to complete the research tasks, numerous thematic literature on the work has been studied [1, 6, 8-12]. As a reference material, the research makes use of the observational results of the Service of the Hydrometeorology and Active Influence on Atmospheric Phenomena, Ministry of Emergency Situations of the Republic Armenia.

Hydro- and meteorological research has been conducted in the Marmarik river basin from the 1930s. Nevertheless, from the point of view of meteorological observations, it is one of the least developed territories. The unique meteorological station Hanqavan, located at an altitude of $1957 \mathrm{~m}$, was closed in 2018, thus marking the end of continuous observations in the region. Therefore, the research utilizes observational data from the nearby meteorological stations - Hrazdan and Aparan. Regarding the hydrological observations, at present (year 2019), the basin contains solely three operating posts, the data from which was used in present research.

Notoriously, it is the physic-geographical conditions that determine the peculiarities of formation, sub-annual distribution and temporal change in the runoff, as well as the water and thermic regime. The above-mentioned conditions include: geological and hydrogeological structure, morphometric and morphological elements of the terrain, the average height of the basin, the water supply in the snow, the intensity of the snow-melt rate, the liquid precipitation and its infiltration in the soil, the duration of precipitation, its uneven distribution on the basin area and in time, the evaporation, the lakeiness, soil and vegetation cover, etc. The basin's terrain is of a mountainous type, largely divided by valleys, ravines and watercourses. The hydrogeological conditions are not favorable for the infiltration of surface water, and large underground water storages are absent. The basin climate is continental, with cold winter seasons and moderately warm summer. 
The following methods were used in the present research: the mathematical statistical analysis, the compare and contrast method, extrapolation and correlation, as well as one of the most widely used methods - the normalized integral-difference curves.

\section{Results and discussion}

During the spring flood season, the extreme maximum runoff often takes place in the basin rivers. At this time, the runoff volume reaches $65-80 \%$ that of the whole year. The maximum water spending usually occurs in the end of April - beginning of May, especially the first half of May. The quantitative characteristics of the maximum basin river runoff are characterized by high variability. For instance, the extreme maximum water runoff in the Marmarik river - p. Aghavnadzor demonstrates significant variation between $9,85 \mathrm{~m}^{3} / \mathrm{sec}$ to $86,7 \mathrm{~m}^{3} / \mathrm{sec}$. In order to reveal the key tendencies of the maximum runoff rate changes, the research used the methods of integral-difference curves, modelling and moving average by n-years. For all three operating hydrological points of the Marmarik basin rivers, the normalized integral-difference curves of the maximum runoff have been built (fig. 2). It is important to underline that throughout the last two decades the maximum runoff demonstrates a tendency for decrease in values.

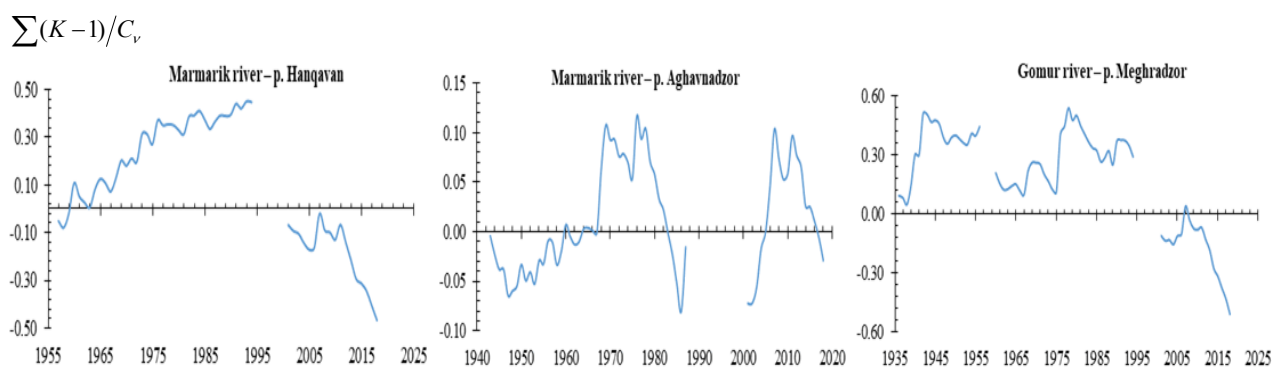

Fig. 2. The integral-difference curves of the extreme maximum water runoff in the Marmarik basin rivers.

As pointed out in the work [7], the normalized integral-difference curves are an effective tool for demonstration, allowing objectively identify the long-period cyclical fluctuations and their parameters. This is highly important for the choice of a representative period for the estimation of key parameters of the probability distribution of the maximum runoff. On fig. 3 it may be seen that throughout the observation period the change in the runoff was followed by a periodical change in the river water content. The change in the maximum runoff of the Marmarik river basin is also characterized by a certain periodic change in the water content of the rivers - cyclicity (low water-level and high water-level runoff phases, of short and long duration). One full cycle, where high and low water-level phases are distinguished, typically lasts 35-45 years containing 5-10 sub cycles. The synchronicity of the maximum runoff is weakly manifested. Fig.3 shows the normalized deviations of the maximum runoff in the $p$. Hanqavan of the Marmarik river. It may be clearly seen from the figure, that the decrease in the absolute values of the maximum runoff is followed by a decrease of the relation of the maximum runoff and the average multipleyear runoff.

In order to analyse the fluctuation tendencies of the maximum water runoff, the research additionally builds upon the linear trend method. The results demonstrate that a decrease in the maximum runoff may be observed on the researched territory (a negative tendency). In other words, it may be assumed that the forecasted hydrological risk level from natural 
disasters rapidly diminished. Similar changes are typical for several other rivers on the CIS territories [3-5, 7, 10-11, 13, 15].

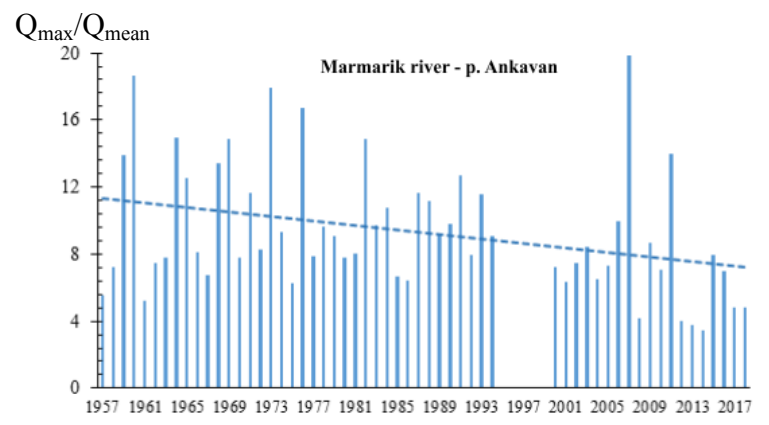

Fig. 3. The normalized deviation of the Marmarik river p. Hanqavan maximum runoff values, throughout the observation period.

This circumstance is mainly due to an increase in air temperature in the cold season (fig. 4), and as a result, an increase in the frequency of thaws, diminishing heights of the snow cover and water storage in the snow layer at the beginning of snow-melt period. The diminishing norm of the absolute value of maximum runoff in the investigated rivers throughout the observational period fluctuates largely, from $18 \%$ to $50 \%$ (table 1 ).
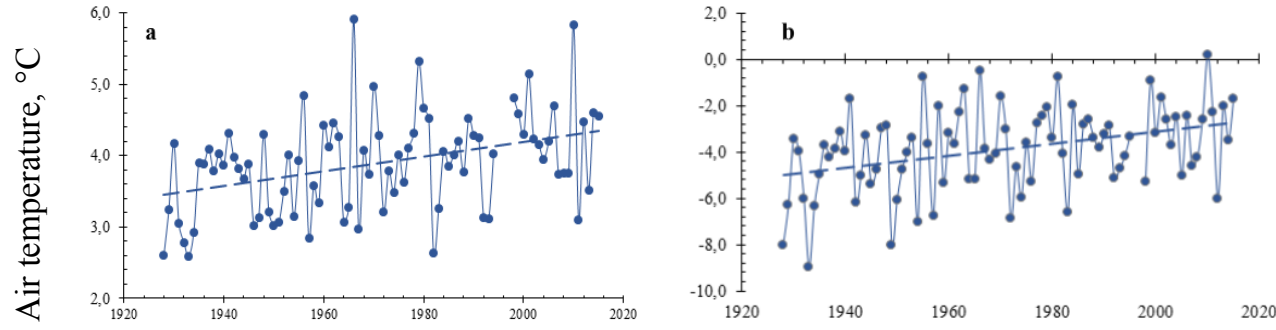

Fig. 4. Inter-year fluctuations of the average air temperature values during the cold season period, built from data of the Hanqavan (a) and Hrazdan (b) weather stations.

Table 1. Change in the characteristics of the absolute maximum runoff values.

\begin{tabular}{|c|c|c|c|c|c|}
\hline \multirow{2}{*}{$\begin{array}{c}\text { River - hydrological } \\
\text { point }\end{array}$} & \multirow{2}{*}{$\begin{array}{l}\text { Linear trend } \\
\text { equation }\end{array}$} & \multirow{2}{*}{$\begin{array}{l}\text { Correlati- } \\
\text { on coeffi- } \\
\text { cient, } \mathrm{r}^{2}\end{array}$} & \multirow{2}{*}{$\begin{array}{l}\text { Norma of the } \\
\text { maximum } \\
\text { runoff, } \mathrm{m}^{3} / \mathrm{sec}\end{array}$} & \multicolumn{2}{|c|}{ Runoff changes } \\
\hline & & & & $\mathrm{m}^{3} / \mathrm{sec}$ & $\%$ \\
\hline Marmarik & $\mathrm{y}=-0$, & 0,107 & 15,7 & -6.38 & $-40,7$ \\
\hline Marmarik - Aghavnadzor & $y=-0,098 x+232,03$ & 0,014 & 39,1 & $-6,96$ & $-17,8$ \\
\hline Gomur - Meghradzor & $y=-0,096 x+204,25$ & 0,082 & 14,9 & $-7,30$ & $-49,0$ \\
\hline
\end{tabular}

For the purposes of estimating the influence of the climate change on the maximum runoff, regression models have been used. They describe the linear dependencies between the runoff elements and climatic factors (such as the air temperature and atmospheric precipitation levels). 
To determine the preliminary or climatic basis state, to be used for comparison with the future forecasts, a large dataset is required, which would include the climate volatility cycles and which would characterize the modern climatic conditions. For an estimation or forecast of the influence of climate change, a quantitative assessment of the future climate change is a prerequisite. At present, there is a lack of methods allowing to perform robustly such assessment. Instead, a so-called set of the future climate scenarios is used. According to the CCSM4 model, the scenarios of the RCP8.5 (equivalent to the SRES A2 scenario) and RCP6.0 (equivalent to SRES B2) emissions for Armenia region, the future changes in air temperature and precipitation levels until year 2100 were developed [2]. Table 2 shows the forecasted changes of the average air temperature and precipitation levels on Armenian territory for the spring period, compared to the average for 1961-1990 period. From the research side, it was taken as a basis of estimation for the Marmarik river maximum runoff reaction in relation to the forecasted climate change.

Table 2. The forecasted change in the average air temperature and the summative atmospheric precipitation levels on the territory of Armenia, throughout the spring period, in relation to the average for 1961-1990 period.

\begin{tabular}{|c|c|c|c|}
\hline Scenarios & $2011-2040$ & $2041-2070$ & $2071-2100$ \\
\hline \multicolumn{4}{|c|}{ Average air temperature, ${ }^{\circ} \mathrm{C}$} \\
\hline RCP6.0 & 1,3 & 2,4 & 2,7 \\
\hline RCP8.5 & 1,4 & 2,7 & 3,9 \\
\hline \multicolumn{3}{|c|}{ Precipitation, $\%$} \\
\hline RCP6.0 & 1,2 & 4,2 & 2,6 \\
\hline RCP8.5 & 4,2 & $-8,0$ & 2,4 \\
\hline
\end{tabular}

Note that, according to the CCSM4 model, the results of the future climate change in general correspond to the previously obtained results on the regional model PRECIS. Nevertheless, the CCSM4 model results are remarkably more successful for temperature than for precipitation levels.

To evaluate the runoff reaction, the relation between the runoff values and the climatic factors (air temperature and atmospheric precipitation levels throughout March-May period) has been examined. As a following step, the changes of the absolute maximum runoff norm in comparison to the average runoff values have been evaluated for the 19611990 period (table 3 ). The estimation was performed based on factual data and climatic scenarios for 2011-2040, 204-2070 and 2071-2100 time intervals. The table demonstrates that before the end of the current century, a clear tendency for decrease may be noted in the year-on-year changes of the maximum runoff norm. Most likely, this is due to the increase in the air temperatures. Such difference of the maximum runoff regime is marked as typical, as well, in the Arctic region [14], and several other rivers on the CIS territories.

Within various scenarios, a different magnitude of changes in the maximum runoff may be observed in the Marmarik river basin. The minimal changes were observed in the first scenario, maximal - in the second. The maximal changes in the average values of the extreme runoff levels, in comparison to the average values for 1961-1990 period, were observed in the Aghavnadzor point of the Marmarik river and Meghradzor of the Gomur river. The corresponding value changes were $13-52 \%$ and $19-59 \%$, accordingly.

In conclusion, the extreme maximum runoff in the Marmarik river basin often occurs during the spring flood season. For all investigated rivers of the basin during the whole observational period, a directed decrease of $18 \%$ and higher of the maximum runoff norm 
(due to climate change) is a typical tendency. Consequently, the danger of flooding has rapidly diminished. The variance of the maximum runoff in the basin rivers is characterized by cyclicity. A full cycle corresponds to a 35-45 year period, containing 5-10 sub cycles.

Table 3. The forecasted changes in the average values of the Marmarik river maximum runoff, in comparison to the average values throughout 1961-1990 period.

\begin{tabular}{|c|c|c|c|c|c|c|c|c|c|}
\hline \multirow{3}{*}{$\begin{array}{c}\text { River- } \\
\text { hydrological } \\
\text { point }\end{array}$} & \multirow{3}{*}{ Scenarios } & \multicolumn{8}{|c|}{ Runoff changes } \\
\hline & & \multicolumn{2}{|c|}{ 1961-1990 } & \multicolumn{2}{|c|}{$2011-2040$} & \multicolumn{2}{|c|}{$2041-2070$} & \multicolumn{2}{|c|}{$2071-2100$} \\
\hline & & $\mathrm{m}^{3} / \mathrm{sec}$ & $\%$ & $\mathrm{~m}^{3} / \mathrm{sec}$ & $\%$ & $\mathrm{~m}^{3} / \mathrm{sec}$ & $\%$ & $\mathrm{~m}^{3} / \mathrm{sec}$ & $\%$ \\
\hline \multirow{2}{*}{$\begin{array}{l}\text { Marmarik - } \\
\text { Hanqavan }\end{array}$} & RCP, 6.0 & 16,9 & 0 & $-2,80$ & $-16,6$ & $-5,2$ & $-30,8$ & $-6,00$ & $-35,5$ \\
\hline & $\mathrm{RCP}, 8.5$ & 16,9 & 0 & $-3,00$ & $-17,8$ & $-6,2$ & $-36,7$ & $-8,70$ & $-51,5$ \\
\hline \multirow{2}{*}{$\begin{array}{l}\text { Marmarik - } \\
\text { Aghavnadzor }\end{array}$} & RCP, 6.0 & 37,9 & 0 & $-5,01$ & $-13,2$ & $-10,6$ & $-28,0$ & $-12,7$ & $-33,5$ \\
\hline & RCP, 8.5 & 37,9 & 0 & $-4,81$ & $-12,7$ & $-15,6$ & $-41,2$ & $-19,7$ & $-52,0$ \\
\hline \multirow{2}{*}{$\begin{array}{l}\text { Gomur - } \\
\text { Meghradzor }\end{array}$} & $\mathrm{RCP}, 6.0$ & 15,6 & 0 & $-3,00$ & $-19,2$ & $-5,30$ & $-34,0$ & $-6,30$ & $-40,4$ \\
\hline & $\mathrm{RCP}, 8.5$ & 15,6 & 0 & $-2,90$ & $-18,6$ & $-7,60$ & $-48,7$ & $-9,20$ & $-59,0$ \\
\hline
\end{tabular}

The reported study was funded by Russian Foundation for Basic Research (No. 18-47242002), Government of Krasnoyarsk Territory, Krasnoyarsk Regional Fund of Science, to the research project: "The development of technology for creating intelligent information systems of object-oriented monitoring of territories based on remote sensing data".

\section{References}

1. A.V. Apukhtin, M.V. Kumani, Scientific bulletins of the Belgorod State University. Series: Natural Sciences. 21 (218), 7 (2015)

2. Armenia's Third National Communication on Climate Change. Ministry of Nature Protection of the Republic of Armenia. (Yerevan: Lusabats. 2015)

3. N.L. Frolova, P.A. Belyakova, V.Y. Grigoryev, A.A. Sazonov, L.V. Zotov, Water resources. 44 (3), 13 (2017)

4. N.L. Frolova, M.B. Kireeva, S.A. Agafonova, V.M. Evstigneev, N.A. Efremova, E.S. Povalishnikova, Water sector of Russia 4, 17 (2015)

5. A.M. Gareev, P.N. Zaytsev, Herald of the Academy of Sciences of the Republic of Bashkortostan. 21(1), 8 (2016)

6. Hydrography of Armenian SSR. Yerevan: Publishing House of the Arm. SSR Academy of sciences (1981)

7. F.A. Imanov, N.I. Hasanova, Proceedings of the Russian State Hydrometeorological University. 9, 6 (2009)

8. IPCC: Climate Change 2007: The Physical Science Basis. Cambridge University Press, Cambridge, USA (2007)

9. D.V. Magritsky, River runoff and hydrological calculations: practical work with the implementation of computer programs. (M.: Triumph Publishing House, 2014)

10. V.G. Margaryan, Water Sector of Russia. 6 (2019)

11. V.G. Margaryan, Hidrolohiia, hidrokhimiia i hidroekolohiia: The scientific collection. 4 (51), 8 (2018)

12. Surface-Water Resources of the USSR 9(2), (L.: Hydrometeoizdat, 1973)

13. G.R. Safina, V.N. Golosova, Proceedings of Kazan University. Natural Sciences Series. 160 (1), 14 (2018)

14. Shevnina E.V., Construction of Unique Buildings and Structures. 7 (22), 13 (2014)

15. T.G. Vardanian, Proceedings of the Russian State Hydrometeorological University. 46, 8 (2017) 